\title{
The pathobiology of Neisseria gonorrhoeae lower female genital tract infection
}

\author{
Jennifer L. Edwards ${ }^{1,2 *}$ and Emily K. Butler \\ The Center for Microbial Pathogenesis, The Research Institute at Nationwide Children's Hospital, The Ohio State University, Columbus, OH, USA \\ 2 The Department of Pediatrics, The Ohio State University, Columbus, OH, USA
}

Edited by:

Cynthia N. Cornelissen, Virginia

Commonwealth University School of

Medicine, USA

\section{Reviewed by:}

Margaret E. Bauer, Indiana University School of Medicine, USA

Daoguo Zhou, Purdue University, USA

\section{*Correspondence:}

Jennifer L. Edwards, The Research

Institute at Nationwide Children's

Hospital, 700 Children's Drive, W503,

Columbus, OH 43205, USA.

e-mail:edwardsj@ccri.net
Infection and disease associated with Neisseria gonorrhoeae, the gonococcus, continue to be a global health problem. Asymptomatic and subclinical gonococcal infections occur at a high frequency in females; thus, the true incidence of N. gonorrhoeae infections are presumed to be severely underestimated. Inherent to this asymptomatic/subclinical diseased state is the continued prevalence of this organism within the general population, as well as the medical, economic, and social burden equated with the observed chronic, disease sequelae. As infections of the lower female genital tract (i.e., the uterine cervix) commonly result in subclinical disease, it follows that the pathobiology of cervical gonorrhea would differ from that observed for other sites of infection. In this regard, the potential responses to infection that are generated by the female reproductive tract mucosa are unique in that they are governed, in part, by cyclic fluctuations in steroid hormone levels. The lower female genital tract has the further distinction of being able to functionally discriminate between resident commensal microbiota and transient pathogens. The expression of functionally active complement receptor 3 by the lower, but not the upper, female genital tract mucosa; together with data indicating that gonococcal adherence to and invasion of primary cervical epithelial cells and tissue are predominately aided by this surfaceexpressed host molecule; provide one explanation for asymptomatic/subclinical gonococcal cervicitis. However, co-evolution of the gonococcus with its sole human host has endowed this organism with variable survival strategies that not only aid these bacteria in successfully evasion of immune detection and function but also enhance cervical colonization and cellular invasion. To this end, we herein summarize current knowledge pertaining to the pathobiology of gonococcal infection of the human cervix.

Keywords: Neisseria gonorrhoeae, complement receptor 3, phospholipase, Akt, nitric oxide, uterine cervix, bacterial adherence and invasion, integrin signaling

\section{INTRODUCTION}

Health complications resulting from Neisseria gonorrhoeae (the gonococcus) disease occur mainly in women and are largely attributed to the predominately asymptomatic nature of lower genital tract, i.e., cervical, infection. Untreated, subclinical infection of the cervix can lead to upper genital tract involvement (e.g., salpingitis) and, potentially, to infertility. Consistent with the different clinical manifestations of disease observed between males (mostly acutely symptomatic) and females, the gonococcus uses variable mechanisms of pathogenesis that are dependent upon the host target cell, the specific microenvironment encountered within its (sole) human host, as well as strain-specific differences prevalent among $N$. gonorrhoeae strains. These include a repertoire of mechanisms to evade the host immune response and antimicrobial agents, to detoxify reactive oxidants, and to acquire iron during residence of the human host.

The gonococcus predominately infects and colonizes the mucosal epithelium of the human urogenital tract. Although gonococcal vaginitis develops in female children in which menarche has not yet occurred, keratinization occurring with menarche prevents gonococcal vaginitis in the adult female. Thus, after the onset of menarche, the clinical presentation of gonococcal disease is not varied. Gonococcal cervicitis results from urogenital gonococcal infection in females. Historically, conflicting models of gonococcal cervicitis have existed. Recent years have brought a resurgent interest in elucidating the molecular/cellular mechanisms contributing to cervical infection and its colonization, as well as in new technologies and model systems by which to examine many unanswered questions. It is now appreciated that not only are both the ecto- and the endocervix permissive for gonococcal infection/colonization but also that the gonococcus can no longer be considered a strictly extracellular pathogen (Evans, 1977; Edwards et al., 2001).

Although various models are commonly used to study N. gonorrhoeae disease, this pathobiology cannot be completely mirrored using any single model system. Each model is limited in its utility when attempting to extrapolate these data to infection and disease in vivo. For example: (1) Human-specific constituents implicated in gonococcal pathogenesis are lacking in animal models; (2) molecular and cellular expression patterns, as well as functional responses, become altered during the immortalization/malignancy of cells lines; (3) primary cells and organ culture do not incorporate exogenous host factors; and (4) only a fixed, often undefined, window or duration of infection may be represented by clinical (naturally acquired/infected human tissues and fluids) specimens. Further, 
although studies have been performed using human volunteers, the asymptomatic nature of gonococcal cervicitis together with the risk for chronic disease sequelae in women, ethically restricts studies to males, and these investigations are limited to only those processes occurring early during the infection process as antibiotic therapy is given immediately with the onset of disease symptoms.

The present manuscript is not a global review of gonococcal pathogenesis; rather, data derived from the use of cervical cell models are reviewed in an effort to highlight those events potentially contributing to cervical infection and disease in vivo. Several comprehensive reviews of N. gonorrhoeae pathogenesis are published (Woods and McGee, 1986; Ram et al., 1999; Dehio et al., 2000; Kline et al., 2003; Edwards and Apicella, 2004; Hamilton and Dillard, 2006; Seib et al., 2006; Steichen et al., 2008; Virji, 2009; Sadarangani et al., 2010; Srikhanta et al., 2010). The reader is also directed to the accompanying papers comprising this current, N. gonorrhoeae-focused, volume of Frontiers in Cellular and Immunity Microbiology for more information.

\section{SURFACE STRUCTURES MEDIATING ADHERENCE}

Included among the better-studied neisserial adhesins are: (1) porin, the major outer membrane protein; (2) the opacity-associated (Opa) proteins; proteins represented by $\mathrm{Opa}_{50}$ adhere to heparin sulfate proteoglycans (HSPGs); whereas, proteins represented by $\mathrm{Opa}_{52}$ bind specific carcinoembryonic antigen-related cell adhesion molecules (CEACAMs); (3) lipooligosaccharide (LOS), a major glycolipid of the gonococcus outer membrane, which lacks the repeating $\mathrm{O}$-antigen of lipopolysaccharide; and (4) type IV-A pili, long polymers of pilin proteins that extend from the gonococcus surface. Multiple gonococcal surface molecules, functioning independently or concertedly, participate in the varied mechanisms currently described as mediating adherence to human (cervical) epithelial cells. Additionally, an impressive number of gonococcal constituents randomly undergo phase (high frequency on/off expression) and/or antigenic (high frequency epitope switching) variation, providing great elasticity in the repertoire of surface antigens that are presented in situ during the course of gonococcal disease (Apicella et al., 1987; Schneider et al., 1991; Jerse et al., 1994; Seifert et al., 1994).

The importance of the above phenomena to in vivo infection is only beginning to be fully appreciated (Kline et al., 2003; Srikhanta et al., 2010; Jennings et al., 2011). Redundant adherence mechanisms have the potential to increase the overall success of the gonococcus in establishing disease, but there is greater evidence to support host-gonococcus interactions as discriminate cell-, site-, and gender-specific adhesion events (reviewed in Edwards and Apicella, 2004). Hence, it is likely that not all available adhesion mechanisms are actually used by this organism during the course of infection/colonization of any specific site. For example, whereas pilus-mediated adherence is critical to a gonococcus-epithelial cell interaction (Swanson, 1977), the Opa proteins appear to dictate adherence to neutrophils and other cells comprising the immune system (Sadarangani et al., 2010). Likewise, an interaction occurring between gonococcal ribosomal protein, L12, and the lutropin receptor (LHr; Spence et al., 1997, 2002) would be confined to the upper female genital tract because of its in vivo tissue distribution (Reshef et al., 1990). Additional/alternative surface constituents certainly contribute to adherence, colonization, and the pathogenesis of these highly human adapted bacterial pathogens in vivo, although their role in mediating a diseased state is less-well defined or has yet to be defined.

\section{INFECTION IN MALES AND TRANSMISSION TO A FEMALE PARTNER}

Neisseria gonorrhoeae infection in men presents as an acute urethritis in which epithelial cells lining the urethra produce pro-inflammatory mediators; e.g., TNF- $\alpha$, IL-6, IL-8, and IL-1 $\beta$ (Ramsey et al., 1995; Harvey et al., 2002); in response to infection. Neutrophil chemotaxis to the site of infection perpetuates this inflammatory state as these cells generate additional pro-inflammatory mediators upon attempting to clear infection. It is this neutrophil influx, together with the shedding of damaged urethral epithelial cells, that accounts for the purulent urethral discharge, which is characteristic of gonococcal disease in men.

Using primary male urethral epithelial cells, urethral tissue, and clinical urethral exudates it is shown that urethral infection is likely established by a step-wise process involving two separate host cell surface molecules, i.e., I-domain-containing $\beta_{1}$-integrins (Edwards and Apicella, 2005) and the asialoglycoprotein receptor (ASGP-R; Harvey et al., 2001b). Adherence to the urethral mucosa is initially mediated by pilus binding to the I-domain region of $\alpha_{1} \beta_{1}$ or $\alpha_{2} \beta_{1}$ integrins. The gonococcus-bearing integrin then forms a transient interaction with the ASGP-R (Edwards and Apicella, 2005). This results in a tight association between the bacterial and urethral cell membranes (Harvey et al., 2001b), and, presumably, aids host cell invasion by poising the bacterium in such a way to enable binding of the terminal galactose of LOS to the ASGP-R and/or by refining the host cell signaling events required for bacterial uptake. A host-derived membrane pedestal is formed beneath the bound gonococcus (Apicella et al., 1996; Harvey et al., 1997). Bacteria are then internalized by an actin- (Giardina et al., 1998) and clathrindependent (Harvey et al., 1997) process. Although the intracellular fate of the gonococcus remains ill-defined, available data support gonococci-containing vacuoles as entering the endosomal recycling pathway as dictated by the ASGP-R (Harvey et al., 2001b).

Neisseria gonorrhoeae are observed intracellularly within the shed urethral epithelial cells and in the neutrophils comprising clinical exudates. Whereas Opa proteins are not required for an interaction with the urethral epithelium, they do play a role in the interaction of gonococci with (resident and recruited) neutrophils (Rest et al., 1982). Opaque gonococci are selected during male urethral infection (Schneider et al., 1995; Schmidt et al., 2000), as are those gonococci that specifically harbor a terminal lacto- $N$-neotetraose (LNnT) moiety on their LOS (Apicella et al., 1987; Schneider et al., 1991). LNnT mimics the paragloboside moiety prevalent on human cells (Harvey et al., 2001a). This form of molecular mimicry presumptively provides one means by which gonococci escape immune detection as (1) analysis of $N$. gonorrhoeae strains demonstrates the predominance of the LNnT epitope among gonococci (Campagnari et al., 1990; John et al., 1999) and (2) the LNnT epitope is selected in men during human volunteer studies as well as with naturally acquired gonococcal urethritis (Schneider et al., 1991, 1988).

The LNnT moiety terminates in a galactose residue that is capable of being sialylated by a sialytransferase present within the gonococcal outer membrane (Shell et al., 2002). LOS sialylation provides 
another level of immune avoidance as well as playing a further role in the deactivation of some innate immune effectors (de la Paz et al., 1995; Gulati et al., 2005; Wu and Jerse, 2006). Therefore, it is not surprising that gonococci isolated from male urethral exudates do display sialic acid on their LOS (Apicella, et al., 1990; Parsons et al., 1992). However, LOS sialylation also impairs binding to the ASGP-R (Harvey et al., 2001b), the invasion of epithelial cell lines (van Putten, 1993; van Putten and Robertson, 1995), the ability to cause disease in human volunteers (Schneider et al., 1996), and the uptake of gonococci by neutrophils (Kim et al., 1992; Rest and Frangipane, 1992). Thus, if sialylation reduces gonococcal infectivity of the male urethra, how then is diseased established in men during the first days following exposure? This apparent conundrum is probably best resolved in view of disease progression and transmission.

Lacking the ability to synthesize cytosine $5^{\prime}$-monophosphate $N$-acetylneuraminic acid (CMP-NANA), the gonococcus must parasitize this sialic acid precursor from its human host. Gonococcal infectivity is restored upon sialic acid removal from LOS by the actions of local neuraminidase or by the replication of gonococci within the lumen of the urethra, an environment lacking hostderived CMP-NANA. Neuraminidase and the ASGP-R are present on human sperm as are identified [CD46 (Källström et al., 1997), I-domain-containing $\beta 1$ integrins (Edwards and Apicella, 2005)] and potentially unidentified (Kirchner et al., 2005) receptors for pili.

Clinically isolated gonococci bear a predominance of pili on their surface (Seifert et al., 1994). Although piliated gonococci bind more readily to human sperm than do non-piliated bacteria (James-Holmquest et al., 1974), the role of any specific pili receptor in mediating an interaction with sperm has not been examined. Nevertheless, any receptor-pilus interaction would likely anchor gonococci in proximity to neuraminidase such that they are capable of becoming desialylated. Following the removal of sialic acid, gonococcal adherence to the spermatozoa-associated ASGP-R would be anticipated (Harvey et al., 2000), which in turn, facilitates disease transmission with copulation.

Neuraminidases are also associated with neutrophil and macrophage cells, and gonococci exhibit resistance to the cytotoxic activity of these immune cells (Shafer and Rest, 1989; Seib et al., 2005; Criss et al., 2009). In this scenario, desialylation of gonococci juxtaposed to neuraminidase could contribute to disease progression in that viable bacteria released from the hostile intracellular environment of the phagocyte would once again be free to invade the urethral epithelium via the ASGP-R. In this way, a diseased state would perpetuate. In summary, gonococci transmitted to the sexual partner of an infected male are likely opaque, piliated (Seifert et al., 1994), and may or may not bear a sialylated LOS. However, whether gonococci are sialylated does not appear to influence colonization of the lower female genital tract (Edwards and Apicella, 2002), but neuraminidases present within the female genital tract may prime the gonococcus for transmission and adherence to the urethral epithelium of a male partner.

\section{THE CERVICAL MICROENVIRONMENT}

The female genital tract presents a number of physical and immunological barriers to deter potential pathogens while simultaneously maintaining a diverse and abundant resident microflora. In this regard, the cervix plays a pivotal role in maintaining the health of the upper female genital tract (and, potentially, a developing fetus), and a healthy normal flora is associated with a decreased risk for sexually transmitted infections. Gardnerella vaginalis and Lactobacilli sp. are the most common residents of the female reproductive tract with $L$. iners and L. gasseri being the most predominant Lactobacilli species (Nikolaitchouk et al., 2008). Several studies suggest that Lactobacillican inhibit an association with host cells and/or impair the in vitro growth of pathogenic organisms (Skarin and Sylwan, 1986; Klebanoff et al., 1991). However, there is also evidence to indicate that data obtained from in vitro-based assays may not accurately project how Lactobacilli affect the fate of a potential pathogen during the course of infection (Meunch et al., 2009; O'Hanlon et al., 2010). We are only beginning to understand how resident microbiota maintain a healthy mucosal environment within the lower female genital tract. Nevertheless, with respect to Lactobacilli, the production (by select strains) of lactic acid, bacteriocins, and hydrogen peroxide each likely contribute to a physiologically balanced status, but their effect on preventing or prohibiting infections requires further study.

\section{N. GONORRHOEAEASSOCIATION WITH CERVICAL EPITHELIA}

The predominance of $\mathrm{iC} 3 \mathrm{~b}$, the inactivated cleavage product of complement protein $\mathrm{C} 3 \mathrm{~b}$, on the surface of clinically isolated gonococci suggests a role for the alternative complement pathway in modulating disease in women (Jarvis, 1994; McQuillen et al., 1999; Vogel and Frosch, 1999). CR3, the $\alpha_{\mathrm{m}} \beta_{2}$ (or CD11b/CD18) integrin, is highly expressed on the human cervix (Edwards et al., 2001). iC3b is the primary natural ligand of CR3 and binds to the I-domain region of CD11b. Gonococcal infection studies using primary human cervical epithelial (pex) cells and quantitative analyses of clinical biopsies obtained from women with culture-documented cervical gonorrhea demonstrate that greater than $92 \%$ of gonococci co-localize with CR3 in vivo (Edwards et al., 2001). This implicates CR3 as the elemental receptor promoting infection of the cervix. Adherence to the cervical epithelium occurs in a sequential manner in which both host and gonococcal constituents cooperate (Edwards et al., 2002) (Figure 1). Pilus binding to the CR3 I-domain places the bacterium in proximity to the cervical cell surface where complement proteins (produced by the cervix) are in sufficient concentrations to allow efficient $\mathrm{C} 3 \mathrm{~b} / \mathrm{iC} 3 \mathrm{~b}$ opsonization to occur, which is essential to the infection process (Edwards et al., 2002). However, pilus binding to the CR3 I-domain also plays an additional role in tempering the activation state of CR3 on the host cell surface (Jennings et al., 2011) that in turn could modulate the downstream cervical cell signaling events triggered with CR3 engagement.

Gonococcal pilus is covalently modified with an O-linked galactose ( $\alpha 1-3)$-2,4-diacetimido-2,4,6-trideoxyhexose (Gal-DATDH) disaccharide (Hegge et al., 2004). As the ( $p g l$ ) genes involved in the biosynthesis and presentation of this glycan are under phase-variable control, in vivo the mature gonococcal pilin possesses either a mono- (DATDH) or a disaccharide (Gal-DATDH). Integrins (e.g., CR3) rapidly oscillate in a dynamic equilibrium between active and inactive conformational states in which the inactive conformation is prevalent under normal physiological conditions. High-affinity receptor function is obtained upon ligand binding. We recently show that the pilin glycan is required to bind to the CR3 I-domain when it is in a closed, low-affinity, conformation, and to confer an 


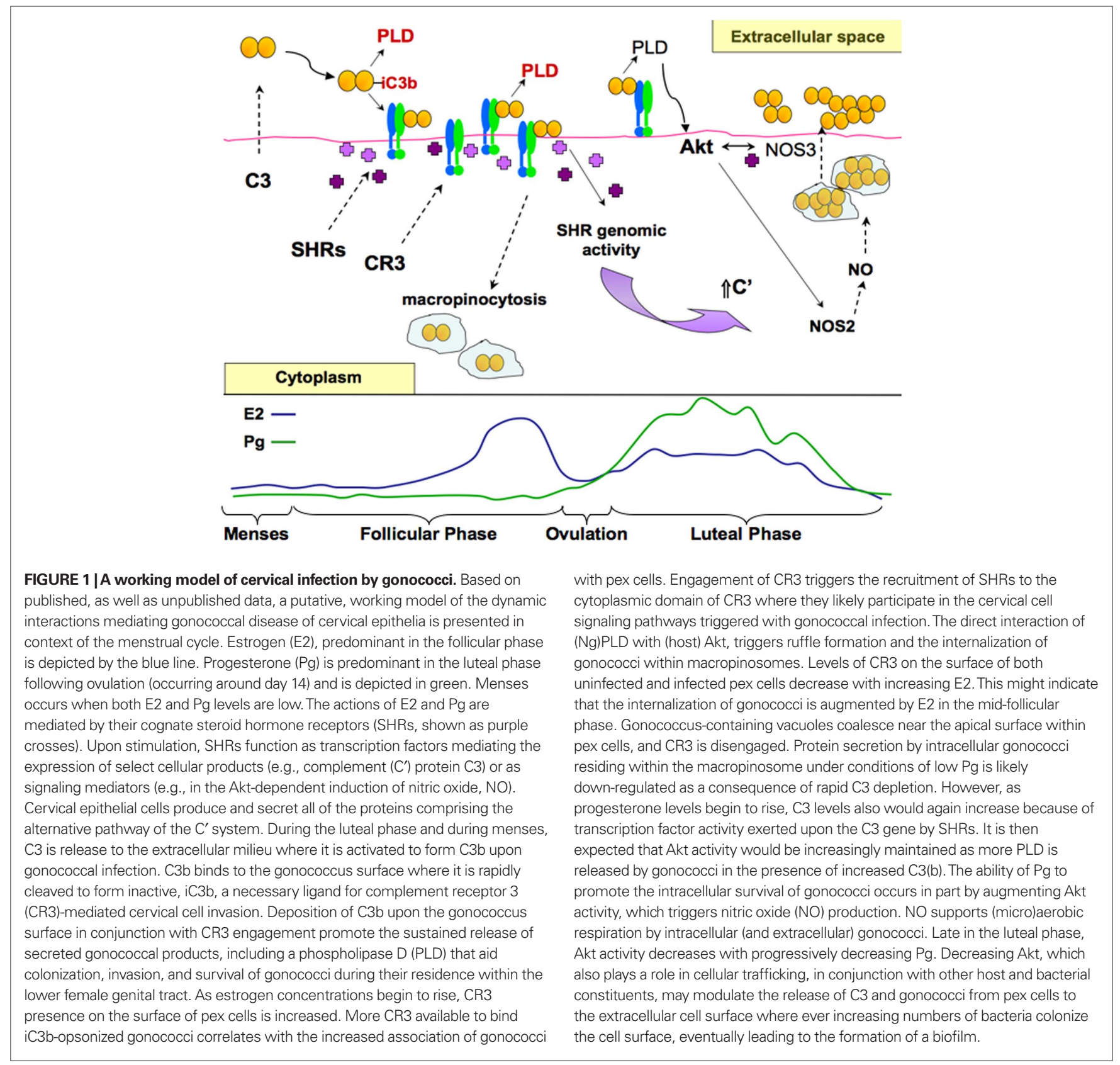

active state to CR3 (Jennings et al., 2011). We additionally show that mutant bacteria bearing only a monosaccharide, or no glycan, on their pili were dramatically impaired in their ability to invade and/or to survive within pex cells. Although these data are highly supportive of a role for the pilin glycan in providing a survival advantage to (pilin-)glycosylated gonococci during cervical infection, further analyses are required to determine if CR3 engagement by pilin glycan-deficient gonococci results in a host cell response that is substantively different from that observed for wildtype gonococci (capable of phase-variable pilin glycosylation). The activity state of CR3 is linked to its phagocytic function as well as to the cellular toxicity of those cells on which this receptor is expressed. Therefore, it is not unreasonable to speculate a role for CR3 in mediating the inflammatory response to infection and to propose that pilus engagement of the CR3 I-domain tempers this response.

$\mathrm{iC} 3 \mathrm{~b}$ and porin serve as secondary adhesins, also binding to the CR3 I-domain. In this way, a tight gonococcus-receptor interaction is likely achieved. Several studies demonstrate that iC3b-mediated adherence to the I-domain of CR3 does not result in a pro-inflammatory response in professional phagocytic cells. Consistent with data discussed above, we have proposed that the cooperative binding of pilus, $\mathrm{iC} 3 \mathrm{~b}$, and porin to this region of CR3 may contribute to the asymptomatic nature of gonococcal cervicitis. Further support for this idea is that: (1) CR3 is not expressed by the urethral epithelium in men in which gonococcal infection is profusely symptomatic, (2) 
the expression of CR3 decreases progressively from the ectocervix (very high expression, asymptomatic disease predominant) to the fallopian tubes (very low/limited expression, symptomatic disease predominant; Edwards et al., 2001),(3) infection of the anorectal mucosa, which potentially expresses CR3 protein (Hussain et al., 1995), also results in predominately asymptomatic disease, and (4) immortalization of primary cervical epithelial cells results in the loss of CR3 expression and the production of pro-inflammatory mediators in response to gonococcal infection (Fichorova et al., 2001). In contrast, the production of pro-inflammatory cytokines by pex cells is down-regulated during gonococcal challenge.

\section{ALTERNATIVE MECHANISMS OF ADHERENCE AND INVASION}

Data obtained from the use of established epithelial cell lines (which do not express CR3; Edwards et al., 2001), suggest that alternative mechanisms of adherence/invasion might occur during the course of gonococcal cervicitis or might promote progressive disease. Mechanisms involving LOS-, Opa-, and porin-mediated adherence and/or invasion are described for various cell lines.

As noted, adherence to primary male urethral epithelial cells is mediated by the concerted actions of pilus binding to I-domaincontaining $\beta 1$-integrins and of LOS adhesion to the ASGP-R (Harvey et al., 2001b). Although the ASGP-R is present within the female genital tract, it does not appear to mediate gonococcal infection of pex cells. However, the co-localization of gonococci with the ASGP-R on endometrial epithelium (Timmerman et al., 2005) could indicate that the ASGP-R plays a role in ascending infection in women. Challenge of ME-180 (omentum metastatic cervical epidermoid carcinoma) cells with a panel of LOS truncation mutants show adherence and invasion comparable to that of the wildtype strain (Minor et al., 2000). One exception was that the adherence and invasion of a $l g t \mathrm{~F}$ mutant was significantly impaired. This suggests that under some conditions LOS might promote cervical infection.

The LOS core region is comprised of two L-glycero-D-mannoheptopyranose (heptose, Hep) and two 2-keto-3-deoxyoctulosonic acid (KDO) residues. The heptose molecules serve as docking sites for short (6-10 sugar moieties) oligosaccharide addition(s). During the biosynthesis of the LOS oligosaccharide, a single glucose is added to the Hep-KDO core structure. LgtF then functions to add a galactose ( $\mathrm{Gal}$ ) to this basal glucose $(\mathrm{Glc})$ residue to yield a Galß1-4Glc1-4Hep1-5KDO. A lgtF mutant can then be described as harboring a single glucose addition on the Hep-KDO core structure. Given that adherence to the ASGP-R is dependent upon galactose recognition, an interaction occurring between a host cell and a lgtF mutant would not be expected to involve the ASGP-R. Further, parallel studies performed using Opa-deficient gonococci showed a reduction in adherence and invasion for all of the mutant strains studied, indicating an Opa-dependence (under the conditions assayed) in the gonococcus-ME-180 cell association (Minor et al., 2000); whereas, the LOS-ASGP-R interaction (as described) occurs independently of Opa proteins.

Data presented by Virji et al. (1996) suggest that greater than $90 \%$ of clinical isolates are able to bind to CEACAM1, suggesting a role for Opa in modulating infection, in vivo. However, no mention of the anatomical site of isolation (e.g., the male urethra or the female cervix) for these bacteria is presented. Opa-expressing gonococci also predominate in isolates obtained from a mouse model of gonococcal infection. In that the structural differences observed between human and murine CEACAM1 likely prohibit an Opa-murine CEACAM1 interaction, alternative factors presumptively select for an Opa+ phenotype during gonococcal challenge (Simms and Jerse, 2006). In this regard, a correlation is made with the presence/absence of Opa proteins on clinically isolated N. gonorrhoeae and the site of isolation (Morse and Brooks, 1985). Isolates obtained from men tend to express Opa proteins (Jerse et al., 1994) as do cervical isolates obtained from women at the time of ovulation (i.e., midcycle). Opa- organisms predominate in asymptomatic men; in cervical isolates obtained during menses; in the fallopian tube; and in genital, blood, and joint fluid obtained from patients with disseminated gonococcal infection. These data have led to the suggestion that Opa- organisms are typically associated with asymptomatic, invasive, disease, whereas Opa+ gonococci are usually associated with symptomatic disease and rarely with complicated, invasive, disease (Morse and Brooks, 1985). Opa proteins mediate the interaction of gonococci with neutrophils (Virji and Heckels, 1986; Naids et al., 1991). Therefore, the predominance of Opa-expressing gonococci in isolates obtained from mice, men, and the (human) cervix at the time of ovulation may be related to an increased presence of neutrophils in proximity to gonococci. Neutrophil influx accompanies gonococcal disease in mice and in men, and immune cells normally (in the absence of infection) infiltrate vaginal tissue and secretions during (human) ovulation.

Although Opa proteins do not mediate the association of gonococci with primary epithelial cells (Harvey et al., 2001b; Swanson et al., 2001; Edwards et al., 2002), several groups demonstrate a role for Opa proteins in mediating gonococcal adherence and invasion of immortalized and/or transfected epithelial cell lines. Opa-mediated adherence can occur directly or indirectly. Bessen and Gotschlich (1986) show that the majority of gonococci tightly associated with HeLa cervical adenocarcinoma cells express Opa and, further, that continued adherence occurs independently of pili. The predominance of OpaA-expressing gonococci in this cellassociated population suggests that this interaction was mediated by HSPGs. Opa-mediated adherence to HSPGs is generally dependent upon vitronectin or fibronectin that function as bridging molecules mediating adherence with an integrin $\left(\alpha_{v} \beta_{3}, \alpha_{v} \beta_{5}\right.$, or $\left.\alpha_{v} \beta_{1}\right)$ co-receptor (Duensing and van Putten, 1997; Gómez-Duarte et al., 1997; van Putten et al., 1998b). A direct Opa-HSPG interaction is also demonstrated in HeLa and Chang, immortal conjunctiva epithelial cells (Grassmé et al., 1997). Similarly, the Opa-CEACAM interaction occurs as a direct protein-protein interaction (Virji et al., 1996, 1999; Popp et al., 1999).

An Opa-CEACAM interaction is also shown to mediate the association of gonococci with professional phagocytic cells (Virji and Heckels, 1986; Naids et al., 1991), B- and T-cells (Boulton and Gray-Owen, 2002; Pantelic et al., 2005), as well as endothelial cells (Muenzner et al., 2000). However, as aberrant expression of CEACAMs is frequently reported for immortal epithelial cell lines, it is currently not clear if an epithelial CEACAM-gonococcus interaction occurs during the course of in vivo gonococcal cervicitis. Invasion of pex cells is increased when challenged with Opa- mutant gonococci or in the presence of anti-CEACAM antibody (Edwards et al., 2002). These data might indicate that, although the majority of 
bacteria associate and invade pex cells via CR3, a small subpopulation of gonococci potentially invade via an Opa-CEACAM interaction, which does not support their intracellular survival. Consistent with this idea is that CEACAM-mediated invasion of transfected HeLa cells results in the acidification of gonococci-containing vacuoles and the death of intracellular gonococci (Booth et al., 2003; McCaw et al., 2004). Co-localization of intracellular gonococci with CEACAMs (as well as CD46) is observed with extended infection of polarized pex cells (Edwards et al., 2000); perhaps suggesting a role for these molecules in the intracellular trafficking of gonococci or in promoting disease by an as yet undefined mechanism(s). The expression of CEACAMs on the mucosal surface of the female genital tract increases from the cervix to the fallopian tubes. Gonococci co-localize with CEACAMs on the luminal face of endometrial tissue (Timmerman et al., 2005). These data hint at a role for a CEACAMgonococcus interaction in augment ascending infection in women; however, further studies to elucidate how ascending infection may progress in women are needed.

Porin of either a P.IA or a P.IB isotype can bind to the I-domain of CR3. However, under low-phosphate conditions, porin of a P.IA isotype mediates entry into HeLa and Chang cells (van Putten et al., 1998a; Kuhlewein et al., 2006). Rechner et al. (2007) have revealed that the heat shock protein, Gp96, functions in conjunction with the scavenger receptor, SREC, to promote invasive low-phosphatedependent infection (LPDI). The significance of LPDI to in vivo gonococcal cervicitis is unclear. However, Kuhlewein et al. (2006) annunciate that LPDI of host cells may promote disseminated disease because: (1) LPDI is augmented by a heat-labile component of human serum, (2) P.IA-expressing gonococci are more frequently isolated from patients with disseminated gonococcal infection (Cannon et al., 1983), and (3) the physiological levels of phosphate in serum are conducive for such an interaction to occur.

\section{INVASION OF CERVICAL EPITHELIA}

In most immortalized cell lines, gonococcal adherence results in an intimate association between the host and bacterial cell membranes. In contrast, the gonococcus-CR3 interaction on pex cells triggers ruffling. Rho GTPases are activated with CR3 engagement (Edwards et al., 2001). Within minutes the actin-associated proteins, vinculin, and ezrin, form localized focal complexes beneath adherent gonococci (Edwards et al., 2000). Although the signaling pathway is not yet fully defined, the result is extensive rearrangement of the actin cytoskeleton promoting large protrusions of the cervical cell membrane, termed ruffles, which loosely engulf adherent gonococci (Edwards et al., 2000). Gonococci are internalized within macropinosome, i.e., large, spacious, vacuoles, which remain associated with actin and coalesce, without apparent fusion, at the apical surface within the cervical cell cytoplasm. Microscopy analyses of clinical cervical biopsies also demonstrate gonococci engulfed in membrane protrusions reflective of ruffles and within clustered, actin-lined, spacious, vacuoles. Gonococcus-induced ruffling is unique from that described for other pathogenic organisms in that it is specifically triggered by CR3 engagement (Edwards et al., 2001), and gonococci do not possess a type three-secretion system.

CR3 expression appears to be limited to primary cervical epithelia; it is not present on the immortal cell lines examined to date. Thereby, membrane ruffling and macropinocytosis do not mediate invasion of immortalized cell lines, although filopodia and lamellipodia are observed. Thus, among the various described mechanisms of gonococcal invasion, a requirement for actin-mediated cytoskeletal rearrangement appears to be a common factor. Differences exist in the events described as inducing actin rearrangement as well as in the kinetics in which actin is associated with gonococci or gonococcus-containing vacuoles. For example, there are data to indicate that pili, Opa, and/or porin are all capable of initiating the host cell signaling events mediating actin rearrangement. Similarly, actin involvement is transient in some cell lines, whereas in others it is more sustained. Collectively, these conflicting data are reflective of the variable mechanisms used by the gonococcus to invade human cells in conjunction with the highly variable nature of N. gonorrhoeae, even for a single gonococcal strain. In this regard, in vitro elucidation of the host cell signaling effectors mediating gonococcal invasion, in vivo, is extremely problematic and is further complicated when considering the continuum of variable steroid hormone concentrations that occur throughout the female menstrual cycle.

\section{SIGNALING EVENTS AND INTRACELLULAR TRAFFICKING}

Signaling events triggered upon CR3 engagement on pex cells are not fully defined; however, secreted gonococcal products, including a phospholipase D (NgPLD) homolog (Edwards et al., 2003; Edwards and Apicella, 2006), play a role in these events. NgPLD is present in every sequenced $N$. gonorrhoeaestrain to-date (The Broad Institute, http://www.broadinstitute.org/annotation/genome/neisseria_gonorrhoeae/MultiHome.html). N. meningitidis and N. lactima also encode NgPLD; however, the pld homolog present in the genome of the commensal organism, N. lactima, is N-terminally truncated and lacks the predicted Sec signal peptide. Thus, NgPLD activity is presumably relegated to pathogenic Neisseria sp.

NgPLD appears to gain access to the cervical intracellular environment because NgPLD activity is observed in cervical cell cytosolic fractions, this activity is absent when pex cells are challenged with a pld mutant strain, and NgPLD co-immunoprecipitates with cervical cytosolic proteins in pull-down assays. Several bacterial and viral pathogens have developed mechanism to trigger Akt kinase (also known as protein kinase B) signaling pathways. The ability of Akt to inhibit apoptosis as well as to regulate the cell cycle, gene transcription, glucose/nutrient uptake and metabolism, and endocytosis make this kinase an attractive target by which pathogens could subvert normal host cell function. Further, Akt together with phosphatidylinositol phosphates (PtdIns P) play a critical role in regulating the actin cytoskeleton and membrane trafficking. Upon cell stimulation local levels of $\operatorname{PtdIns}(4,5) \mathrm{P}_{2}$ increase and are enriched at sites of bacterial contact as well as in large plasma membrane structures, e.g., lamellipodia and ruffles, which is of particular relevance to gonococcal pathobiology. In general, Akt activation is dependent upon the role of phosphatidylinositol 3-kinase (PI3-K) in PtdIns $(3,4) \mathrm{P}_{2}$ and $\operatorname{PtdIns}(3,4,5) \mathrm{P}_{3}$ formation. PI3-K-independent mechanisms of Akt activation, albeit limited, are also reported (Konishi et al., 1997; Moule et al., 1997; Sable et al., 1997; Filippa et al., 1999; Cenni et al., 2003; Perez-Garcia et al., 2004). Our data strongly suggest that N. gonorrhoeae subvert cervical cell signaling pathways by competing with $\operatorname{PtdIns}(3,4,5) \mathrm{P}_{3}$ (and possibly other phosphoinositides) for Akt binding (Edwards and 
Apicella, 2006). We show NgPLD directly interacts with Akt kinase in a [presumptive, PtdIns $(3,4) \mathrm{P}_{2}$-preserving] $\mathrm{PI} 3-\mathrm{K}$-independent manner to promote membrane ruffling, CR3 recruitment to the cervical cell surface, and the survival of gonococci within pex cells (Edwards and Apicella, 2006). However, a similar study performed using A431 cells, a vulvular epidermal carcinoma cell line, suggest that the pilus retraction motor, PilT, triggers Akt activation in a PI3-K-dependent manner that results in gonococcus microcolony formation (Lee et al., 2005). Both mechanisms of Akt activation may occur in vivo and may differentially augment gonococcus infection during the course of disease.

One consequence of the Akt pathway is the production of nitric oxide (NO) through the actions of nitric oxide synthases (i.e., NOS). In this regard, it is noteworthy that progestin-based contraceptives are shown to increase the susceptibility of a woman to develop gonococcal disease (Louv et al., 1989; Fernandez et al., 2001; Morrison et al., 2004). Gonococci are able to use nitrite and/or nitric oxide (i.e., NOX, collectively) in an alternative respiratory mechanism under microaerobic-hypoxic conditions (Knapp and Clark, 1984). Although clinical data indicate that hormone-induced, cyclic changes occurring to the mucosal epithelium of the female genital tract modulate gonococcal disease; until recently how steroid hormones influence cervical gonorrhea has remained poorly defined. NOX are present in cervical secretions (Väisänen-Tommiska et al., 2003), which are capable of supporting N. gonorrhoeae growth. Overton et al. (2006) have proposed that host-initiated nitric oxide induction of $N$. gonorrhoeae nitric oxide reductase, NorB, could confer a survival advantage to these bacteria in vivo by serving as an energy source under conditions of oxygen limitation. Although $\mathrm{NO}$ is generally considered to exert a cytotoxic effect upon bacterial cells, consistent with this hypothesis, we show progesterone promotes gonococcal survival during pex cell infection by a NgPLDdependent mechanism in which engagement of CR3 leads to Akt kinase activation and, in turn, to NO production (Edwards, 2010). Interestingly, although NO is believed to be a freely diffusible molecule, its spatial distribution during gonococcal infection plays an important role in mediating these processes (Edwards, 2010). Taken together, the above data might indicate that aerobic denitrification by gonococci might have evolved as an adaptation to promote survival during the transition to a microaerobic/anaerobic lifestyle while in residence within the female genital tract where local steroid hormones, in particular progestagens, would bind to the gonococcal membrane and impede oxygen uptake.

In addition to Rho GTPases; PtdIns $(4,5) \mathrm{P}_{2}$ and myosin light chain kinase may also be required for successful gonococcal infection of pex cells (Edwards and Apicella, 2006). Although confirmatory studies have not been performed, these data are consistent with the PtdIns $(4,5) \mathrm{P}_{2}$-enriched plasma membrane patches (PRPMPs) described by Huang et al. (2004) and the role of Rho GTPases in regulating membrane raft aggregation in response to integrin activation (LaCalle et al., 2002). PRPMPs define and are exclusively co-localized with regions of concentrated myosin, actin polymerization, ruffling, and endocytosis (Huang et al., 2004). Additionally, Akt resides within raft-like structures that coalesce into "superrafts” (e.g., PRPMPs; Skaletz-Rorowski et al., 2003). Similarly, CR3 preferentially localizes to, and clusters within, membrane rafts in professional phagocytic cells (Peyron et al., 2000).
Opa-CEACAM-mediated host cell signaling was initially described to involve Src tyrosine kinases, triggering the Rho GTPases, which then resulted in epithelial cytoskeletal rearrangement and gonococci internalization by a PI3-kinase-dependent mechanism (Hauck et al., 1998). Using CEACAM-specific transfected cell lines it is now suggested that CEACAM3-mediated invasion (which is limited to granulocytes) is dependent upon Src. Conversely, CEACAM-mediated invasion of epithelial cells does not require Src (McCaw et al., 2004) and occurs through cholesterolrich membrane microdomains (i.e., rafts; Muenzner et al., 2008; Schmitter et al., 2007). With regard to the Opa-HSPG interaction, phosphatidylcholine-dependent phospholipase $\mathrm{C}$ activation results in the subsequent generation of diacylglycerol, acidic spingomyelinase activation, and ceramide production (Grassmé et al., 1997). In this model, ceramide modulates the cytoskeletal rearrangements required for endocytosis of the cell-associated gonococcus.

Several human pathogens exploit ceramide-enriched microdomains to invade host cells. Although PRPMPs are larger than membrane microdomains, the structure and composition of membrane rafts are variable depending upon the specific cell type in which they reside as well as the particular pathogen that may induce their formation/aggregation (Zass et al., 2005). PRPMPs function to drive membrane ruffling (Huang et al., 2004); however, the ability of a cell to undergo ruffling is, in part, also dependent upon the surface to volume ratio of that cell. In our observation, cervical cells grown as primary cultures exhibit a more columnar appearance than do immortalized cell lines and as a result may be more permissive to PRPMP formation and ruffling. Collectively, the above data suggest that the gonococcus exploits and/or triggers (super-)raft formation within the host cell membrane as a common route by which to gain access to the intracellular environment, albeit by different mechanisms. Whether raft-mediated gonococcal internalization by variable receptor-mediated events results in their residence within a "common" vacuole is not known. However, McCaw et al. (2004) demonstrate that internalization of gonococci by different CEACAM receptors in transfected HeLa cells occurs by distinct endocytic mechanisms after which the gonococcus-containing vacuole appears similar.

\section{INTRACELLULAR FATE}

Generally, endocytosis mediated by membrane rafts does not result in fusion of the raft vesicle with lysosomes. Therefore, as is suggested for diverse microorganisms, the ability of gonococci to enter epithelial cells through raft-like structures could provide theses bacteria with an alternative or additional survival strategy, evading intracellular degradation or triggering signaling pathways within the host cell to produce an intracellular environment conducive to survival and/or enhanced uptake. However, studies using CEACAM-transfected murine fibroblast and/or HeLa cells suggest that gonococci-containing vacuoles acquire phagolysosomal characteristics (Booth et al., 2003; McCaw et al., 2004; Binker et al., 2007). Maturation and perinuclear trafficking of gonococci-containing vacuoles occurs in wildtype or lysosomeassociated membrane proteins (LAMP)-1- or LAMP-2-deficient cells (Binker et al., 2007). In contrast, infection of LAMP-1 and LAMP-2 (double) deficient cells results in gonococci-containing vacuoles remaining at the cell periphery, which did not acquire 
lysosomal characteristics. Collectively, these data indicate a critical role for LAMP-1 and LAMP-2 in maturation of the gonococcuscontaining vacuole and, presumptively, in gonococcal killing.

Gonococci produce an IgA1 protease that is capable of cleaving LAMP-1 (Lin et al., 1997), but not LAMP-2 (Hauck and Meyer, 1997). Epithelial cell lines differ with respect to the level of expression and the glycosylation pattern of LAMP isoforms (Carlsson et al., 1988). The contribution of gonococcal IgA protease in promoting disease in vivo remains controversial. Whereas infection of male volunteers (Johannsen et al., 1999), fallopian tube tissue explants (Cooper et al., 1984), and Chang cells (Hauck and Meyer, 1997) using N. gonorrhoeae IgA protease mutants results in disease/adherence/invasion indistinguishable from that observed with the parental wildtype strain, studies performed using A431 cells result in decreased viability of mutant gonococci when compared to wildtype. However, gonococcal IgA protease either directly or indirectly, respectively, decreases LAMP-1 and LAMP-2 levels in A431 cells (Ayala et al., 1998). Therefore, IgA protease activity could potentially impair delivery of the gonococcus-containing vacuole to the lysosome during A431 cell challenge. Whether these conflicting data can be attributed to specific differences in LAMP expressed by each cell type, to the experimental protocols used, or to additional differences specific to each cell type or to gonococcal strains used, is currently unclear.

Gonococcal infection studies demonstrate that following endocytosis bacteria-containing vacuoles are transcytosed to the basolateral surface of fallopian tube epithelia where they are released to the extracellular space and, thus, are poised to invade the sub-epithelial mucosa (Ward et al., 1975; Johnson et al., 1977; Draper et al., 1980; McGee et al., 1981; Stephens et al., 1987). Adherence to the LHr by the L12 gonococcal protein is proposed to mediate the gonococcusfallopian tube interaction as well as gonococcal transcytosis through HEC-1-B endometrium adenocarcinoma cells (Chen et al., 1991; Gorby et al., 1991; Spence et al., 1997). LHr-mediated gonococcal transcytosis is consistent with the normal function of this receptor in delivering human chorionic gonadotropin to target tissues. In contrast, internalization of leukocyte integrins (e.g., CR3) on transfected epithelial cells occurs via detergent-resistant membrane vacuoles that are sorted to an endocytic polarized recycling pathway (Fabbri et al., 1999, 2005). Although these events are not specifically described for CR3 on cervical epithelia, mutations in the cytoplasmic domain of CD18 (the $\beta 2$ subunit shared among the leukocyte integrins, including CR3) result in aberrant sorting of $\beta 2$-integrin-containing vacuoles from a recycling to a degradative pathway (Fabbri et al., 1999, 2005). Therefore, it is reasonable to propose that engagement of CR3 on cervical epithelia by gonococci results in their entrance into a recycling pathway.

Gonococci replicate within ME-180 (Hagen and Cornelissen, 2006) and pex cells (Wu et al., 2005, 2006; Seib et al., 2007) after which they are released to the extracellular milieu. Although some gonococci traverse the intracellular space and exit pex cells at the

\section{REFERENCES}

Apicella, M. A., Ketterer, M., Lee, F. K., Zhou, D., Rice, P. A., and Blake, M. S. (1996). The pathogenesis of gonococcal urethritis in men: confocal and immunoelectron microscopic analysis of urethral exudates from men infected with Neisseria gonorrhoeae. J. Infect. Dis. 173, 636-646.

Apicella, M.A., Mandrell, R. E., Shero, M., Wilson, M.E., Griffiss, J. M., Brooks, G. F., Lammel, C., Breen, J. F., and Rice, P.

basolateral surface, the majority of gonococci-containing vacuoles remain clustered at the apical cell periphery (Evans, 1977; Edwards et al., 2000), resulting in the majority of gonococci being released from the apical surface without disruption of the cervical cell monolayer (Greiner et al., 2005). These data are consistent with the normal trafficking pathway described for the leukocyte integrins (Fabbri et al., 1999, 2005). Analyses of gonococcal transcytosis through polarized T84 lung metastasis colorectal carcinoma cells by Criss and Seifert (2006) show that, whereas more gonococci exit through the basolateral surface of T84 cells at earlier time points post-challenge, equivalent numbers of gonococci are released from both the apical and basolateral surfaces with extended infection. In this regard, internalized raft(-like) structures are commonly reported to be recycled back to the apical cell surface, although trafficking of rafts to the basolateral surface of epithelial cells is also reported. Others have reported the ability of gonococci to traverse through T84 and HEC-1-B cell monolayers; however, the ability of gonococci to exit apically from these cells was not examined in these studies (Merz et al., 1996; Ilver et al., 1998; Wang et al., 1998, 2007; Hopper et al., 2000). Although there are many striking differences between the immortalized and primary cells described above, collectively, these data indicate that multiple host and/or gonococcal constituents likely contribute to the intracellular fate of gonococci as well as the fate of the gonococcus-containing vacuole. Whereas transcytosis through the cervical epithelium may promote invasion of sub-mucosal tissues, recycling of gonococci-containing vacuoles to the apical cell surface may promote biofilm formation and ascension to the upper female genital tract.

\section{CONCLUSION}

Through co-evolution with their exclusive human hosts the pathogenic Neisseria have developed several mechanisms by which they successfully persist in the general population. Increasing multidrug-resistance among gonococcal strains serves as a reminder of a critical need to further our understanding of the different mechanisms used by $N$. gonorrhoeae to infect and to colonize the specific microenvironments of the female reproductive tract, at different phases of the menstrual cycle, to better understand the morbidity associated with such infections. To this end, a better appreciation of the molecular mechanisms dictating asymptomatic cervical disease will provide sound rationale on which to base identification of subclinical infections, treatment, and prevention of harmful sequelae in the future.

\section{ACKNOWLEDGMENTS}

The Edwards Lab is funded by NIAID grants 1R01AI07639802 and 1R21AI082125-01. A Young Investigator Award, given to Jennifer L. Edwards by the Research Institute at Nationwide Children's Hospital, provided additional support for some of the data described within the present manuscript.

A. (1990). Modification by sialic acid of Neisseria gonorrhoeae lipooligosaccharide epitope expression in human urethral exudates: an immunoelectron microscopic analysis. J. Infect. Dis. 162 506-512.
Apicella, M. A., Shero, M., Jarvis, G. A., Griffiss, J. M., Mandrell, R. E., and Schneider, H. (1987). Phenotypic variation in epitope expression of the Neisseria gonorrhoeae lipooligosaccharide. Infect. Immun. 55, 1755-1761. 
Ayala, P., Lin, L., Hopper, S., Fukuda, M., and So, M. (1998). Infection of epithelial cells by pathogenic neisseriae reduces the levels of multiple lysosomal constituents. Infect. Immun. 66, 5001-5007.

Bessen, D., and Gotschlich, E. C. (1986). Interactions of gonococci with HeLa cells: attachment, detachment, replication, penetration, and the role of protein II. Infect. Immun. 54, 154-160.

Binker, M. G., Cosen-Binker, L. I., Terebiznik, M.R., Mallo, G.V., McCaw, S. E., Eskelinen, E.-L., Willenborg, M., Brummel, J.H., Saftig, P., Grinstein, S., and Gray-Owen, S. D. (2007). Arrested maturation of Neisseria-containing phagosomes in the absence of the lysosome-associated membrane proteins, LAMP-1 and LAMP-2. Cell. Microbiol. 9, 2153-2166.

Booth, J. W., Telio, D., Liao, E. H., McCaw, S. E., Matsuo, T., Grinstein, S., and Gray-Owen, S. D. (2003). Phosphatidylinositol 3-kinases in CEACAM-mediated internalization of Neisseria gonorrhoeae. J. Biol. Chem. 278, 14037-14045.

Boulton, I. C., and Gray-Owen, S. D. (2002). Neisserial binding to CEACAM1 arrests the activation and proliferation of CD4+ Tlymphocytes. Nat. Immunol. 3, 229-236.

Campagnari, A. A., Spinola, S. M., Lesse, A. J., Kwaik, Y. A., Mandrell, R. E., and Apicella, M. A. (1990). Lipooligosaccharide epitopes shared among Gram-negative non-enteric mucosal pathogens. Microb. Pathog. 8, 353-362.

Cannon, J. G., Buchanan, T. M., and Sparling, P. F. (1983). Confirmation of association of protein I serotype of Neisseria gonorrhoeae with ability to cause disseminated infection. Infect. Immun. 40, 816-819.

Carlsson, S. R., Roth, J., Piller, F., and Fukuda, M. (1988). Isolation and characterization of human lysosomal membrane glycoproteins, h-lamp-1 and h-lamp-2. J. Biol. Chem. 263, 18911-18919.

Cenni, V., Sirri, A., Riccio, M., Lattanzi, G., Santi, S., de Pol,A., Maraldi, N.M., and Marmiroli, S. (2003). Targeting of the Akt/PKB kinase to the actin skeleton. Cell. Mol. Life Sci. 60, 2710-2720.

Chen, J. C.-R., Bavoil, P., and Clark,V. L. (1991). Enhancement of the invasive ability of Neisseria gonorrhoeae by contact with HecIB, an adenocarcinoma endometrial cell line. Mol. Microbiol. 5, 1531-1538.

Cooper, M. D., Jeffery, C., and Dever, C. A. (1984). Electron microscope studies of attachment to human fallopian tube mucosa by a gonococcal IgA1 protease deficient mutant and wild type parent. Scan. Electron Microsc. (Pt 4), 1925-1930.
Criss, A. K., Katz, B. Z., and Seifert, H. S. (2009). Resistance of Neisseria gonorrhoeae to non-oxidative killing by adherent human polymorphonuclear leucocytes. Cell. Microbiol. 11, 1074-1087.

Criss, A. K., and Seifert, H. S. (2006). Gonococci exit apically and basally from polarized epithelial cells and exhibit dynamic changes in type IV pili. Cell. Microbiol. 8,1430-1443.

de la Paz, H., Cooke, S. J., and Heckels, J. E. (1995). Effect of sialylation of lipopolysaccharide of Neisseria gonorrhoeae on recognition and complement-mediated killing by monoclonal antibodies directed against different outer-membrane antigens. Microbiology 141, 913-920.

Dehio, C., Gray-Owen, S. D., and Meyer, T. F. (2000). "Host cell invasion by pathogenic Neisseriae," in Subcellular Biochemistry, Vol. 33, Bacterial Invasion into Eukaryotic Cells, eds T. A. Oelschlaeger and J. Hacker (New York, NY: Plenum Publishers), 61-96.

Draper, D. L., Donegan, E. A., James, J. F., Sweet, R. L., and Brooks, G. F. (1980). In vitro modeling of acute salpingitis caused by Neisseria gonorrhoeae. Am. J. Obstet. Gynecol. 138, 996-1002.

Duensing, T. D., and van Putten, J. P. M. (1997). Vitronectin binds to the gonococcal adhesin OpaA through a glycoaminoglycan molecular bridge. Biochem. J. 334, 133-139.

Edwards, J. L. (2010). Neisseria gonorrhoeae survival during primary human cervical epithelial cell infection requires nitric oxide and is augmented by progesterone. Infect. Immun. 78, 1202-1213.

Edwards, J. L., and Apicella, M. A. (2002). The role of lipooligosaccharide in Neisseria gonorrhoeae pathogenesis of cervical epithelia: lipid A serves as a C3 acceptor molecule. Cell. Microbiol. 4, 584-598.

Edwards, J. L., and Apicella, M. A. (2004). The molecular mechanisms used by Neisseria gonorrhoeae to initiate infection differ between men and women. Clin. Microbiol. Rev. 17, 965-981.

Edwards, J. L., and Apicella, M. A. (2005). I-domain-containing integrins serve as pilus receptors for Neisseria gonorrhoeae adherence to human epithelial cells. Cell. Microbiol. 7, 1197-1211.

Edwards, J. L., and Apicella, M. A. (2006). Gonococcal PLD directly interacts with Akt kinase upon infection of primary human cervical epithelial cells. Cell. Microbiol. 8, 1253-1271.

Edwards, J. L., Brown, E. J., Ault, K. A., and Apicella, M. A. (2001). The role of complement receptor 3 (CR3) in Neisseria gonorrhoeae infection of human cervical epithelia. Cell. Microbiol. 3, 611-622.
Edwards, J. L., Brown, E. J., Uk-Nham, S., Cannon, J. G., Blake, M. S., and Apicella, M.A. (2002). A co-operative interaction between Neisseria gonorrhoeae and complement receptor 3 mediates infection of primary cervical epithelial cells. Cell. Microbiol. 4 571-584.

Edwards, J. L., Entz, D. D., and Apicella, M. A. (2003). Gonococcal phospholipase $\mathrm{D}$ modulates the expression and function of complement receptor 3 in primary cervical epithelial cells. Infect. Immun. 71, 6381-6391.

Edwards, J. L., Shao, J. Q., Ault, K. A., and Apicella, M. A. (2000). Neisseria gonorrhoeae elicits membrane ruffling and cytoskeletal rearrangements upon infection of primary human endocervical and ectocervical cells. Infect. Immun. 68, 5354-5363.

Evans, B. A. (1977). Ultrastructure study of cervical gonorrhea. J. Infect. Dis. 136, 248-255.

Fabbri, M., Di Meglio, S., Gagliani, M. C. Consonni, E., Molteni, R., Bender, J. R., Tacchetti, C., and Pardi, R. (2005). Dynamic partitioning into lipid rafts controls the endo-exocytic cycle of the $\alpha \mathrm{L} / \beta 2$ integrin, LFA- 1 , during leukocyte chemotaxis. Mol. Biol. Cell 16, 5793-5803.

Fabbri, M., Fumagalli, L., Bossi, G., Bianci, E., Bender, J. R., and Pardi, R. (1999).A tyrosine-based sorting signal in the $\beta 2$ integrin cytoplasmic domain mediates its recycling to the plasma membrane and is required for ligand-supported migration. EMBO J. 18, 4915-4925.

Fernandez, R., Nelson, P., Delgado, J. Aguilera, J., Massai, R., Velasquez, L., Imarai, M., Croxatto, H. B., and Cardenas, H. (2001). Increased adhesiveness and internalization of Neisseria gonorrhoeae and changes in the expression of epithelial gonococcal receptors in the fallopian tube of copper T and Norplant users. Hum Reprod. 16, 463-468.

Fichorova, R. N., Desai, P.J., Gibson, F.C.III, and Genco, C.A. (2001). Distinct proinflammatory host responses to Neisseria gonorrhoeae infection in immortalized human cervical and vaginal epithelial cells. Infect. Immun. 69, 5840-5848.

Filippa, N., Sable, C. L., Filloux, C. Hemmings, B., and Van Obberghen, E. (1999). Mechanism of protein kinase B activation by cyclic AMPdependent protein kinase. Mol. Cell. Biol. 19, 4989-5000.

Giardina, P. C., Williams, R., Lubaroff, D., and Apicella, M. A. (1998). Neisseria gonorrhoeae induces focal polymerization of actin in primary human urethral epithelium. Infect. Immun. 66 , 3416-3419.

Gómez-Duarte, O. G., Dehio, M. Guzmán, C.A., Chhatwal, G.S., Dehio,
C., and Meyer, T. F. (1997). Binding of vitronectin to Opa-expressing Neisseria gonorrhoeae mediates invasion of HeLa cells. Infect. Immun. 65, 3857-3866.

Gorby, G. L., Clemens, C. M., Barley, L. R., and McGee, Z. A. (1991). Effect of human chorionic gonadotropin (hCG) on Neisseria gonorrhoeae invasion of and IgA secretion by human fallopian tube mucosa. Microb. Pathog. 10, 373-384.

Grassmé, H., Gulbins, E., Brenner, B., Ferlinz, K., Sandhoff, K., Harzer, K., Lang, F., and Meyer, T. F. (1997). Acidic sphingomyelinase mediates entry of Neisseria gonorrhoeae into nonphagocytic cells. Cell 91, 605-615.

Greiner, L. L., Edwards, J. L., Rabinak, C. A., Shao, J. Q., and Apicella, M. A. (2005). Biofilm formation by Neisseria gonorrhoeae. Infect. Immun. 73, 1964-1970.

Gulati, S., Cox, A., Lewis, L. A., Michael, F. S., Li, J., Boden, R., Ram, S., and Rice, P. A. (2005). Enhanced factor H binding to sialylated gonococci is restricted to the sialylated lacto- $N$-neotetraose lipooligosaccharide species: implications for serum resistance and evidence for a bifunctional lipooligosaccharide sialyltransferase in gonococci. Infect. Immun. 73, 7390-7397.

Hagen, T. A., and Cornelissen, C. N. (2006). Neisseria gonorrhoeae requires expression of TonB and the putative transporter TdfF to replicate within cervical epithelial cells. Mol. Microbiol. 62, 1144-1157.

Hamilton, H. L., and Dillard, J. P. (2006). Natural transformation of Neisseria gonorrhoeae: from DNA donation to homologous recombination. Mol. Microbiol. 59, 376-385.

Harvey, H. A., Ketterer, M. R., Preston, A., Lubaroff, D., Williams, R., and Apicella, M. A. (1997). Ultrastructure analysis of primary human urethral epithelial cell cultures infected with Neisseria gonorrhoeae. Infect. Immun. 65, 2420-2427.

Harvey, H. A., Porat, N, Campbell, C. A., Jennings, M. P., Gibson, B. W., Phillips, N. J., Apicella, M. A., and Blake, M. S. (2000). Gonococcal lipooligosaccharide is a ligand for the asialoglycoprotein receptor on human sperm. Mol. Microbiol. 36, 1059-1070.

Harvey, H.A., Post, D. M., and Apicella, M. A. (2002). Immortalization of human urethral epithelial cells: a model for the study of the pathogenesis of and the inflammatory cytokine response to Neisseria gonorrhoeae infection. Infect. Immun. 70, 5808-5815.

Harvey, H.A., Swords, W. E., and Apicella, M.A. (2001a). The mimicry of human glycolipids and glycosphingolipids in the lipooligosaccharides of pathogenic 
Neisseria and Haemophilus. J. Autoimmun. 65, 2420-2427.

Harvey, H. A., Jennings, M. P., Campbell, C. A., Williams, R., and Apicella, M. A. (2001b). Receptor-mediated endocytosis of Neisseria gonorrhoeae into primary human urethral epithelial cells, the role of the asialoglycoprotein receptor. Mol. Microbiol. 42, 659-672.

Hauck, C. R., and Meyer, T. F. (1997). The lysosomal/phagosomal membrane protein h-lamp-1 is a target of the IgAl protease of Neisseriagonorrhoeae. FEBS Lett. 405, 86-90.

Hauck, C. R., Meyer, T. F., Lang, F., and Gulbins, E. (1998). CD66-mediated phagocytosis of Opa52 Neisseria gonorrhoeae requires a Src-like tyrosine kinase- and Rac1-dependent signaling pathway. EMBO J. 17, 443-454.

Hegge, F. T., Hitchen, P. G., Aas, F. E., Kristiansen, H., Lovold, C., EggeJacobsen, W., Panico, M., Leong, W.Y., Bull, V., Virji, M., Morris, H. R., Dell, A., and Koomey, M. (2004). Unique modifications with phosphocholine and phosphoethanolamine define alternate antigenic forms of Neisseria gonorrhoeae type IV pili. Proc. Natl. Acad. Sci. U.S.A. 101, 10798-10803.

Hopper, S, Wilbur, J. S., Vasquez, B. L., Larson, J., Clary, S., Mehr, I. J., Seifert, H. S., and So, M. (2000). Isolation of Neisseria gonorrhoeae mutants that show enhanced trafficking across polarized T84 epithelial monolayers. Infect. Immun. 68, 896-905.

Huang, S., Lifshitz, L., Patki-Kamath, V., Tuft, R., Fogarty, K., and Czech, M. P. (2004). Phosphatidylinositol-4,5bisphosphate-rich plasma membrane patches organize active zones of endocytosis and ruffling in cultured adipocytes. Mol. Cell. Biol. 24,9102-9123.

Hussain, L. A., Kelly, C. G., Rodin, A., Jourdan, M., and Lehner, T. (1995). Investigation of the complement receptor $3(\mathrm{CD} 11 \mathrm{~b} / \mathrm{CD} 18)$ in human rectal epithelium. Clin. Imunnol. Exp. 102, 384-388.

Ilver, D., Källström, H., Normark, S., and Jonsson, A.-B. (1998). Transcellular passage of Neisseria gonorrhoeae involves pilus phase variation. Infect. Immun. 66, 469-473.

James-Holmquest, A. N., Swanson, J., Buchanan, T. M., Wende, R. D., and Williams, R. P. (1974). Differential attachment by piliated and nonpiliated Neisseria gonorrhoeae to human sperm. Infect. Immun. 9,897-902.

Jarvis, G. A. (1994). Analysis of C3 deposition and degradation on Neisseria meningitidis and Neisseria gonorrhoeae. Infect. Immun. 62, 1755-1760. Jennings, M. P., Jen, F. E.-C., Roddam, L. F., Apicella, M. A., and Edwards, J. L.
(2011). The Neisseria gonorrhoeae pilin glycan contributes to CR3 activation during challenge of primary cervical epithelial cells. Cell. Microbiol. doi: 10.1111/j.1462-5822.2011.01586.x. [Epub ahead of print].

Jerse, A. E., Cohen, M. S., Drown, P. M., Whicker, L. G., Isbey, S. F., Seifert, H. S., and Cannon, J. G. (1994). Multiple gonococcal opacity proteins are expressed during experimental urethral infection in the male. J. Exp. Med. 179, 911-920.

Johannsen, D. B., Johnston, D. M., Koymen, H. O., Cohen, M. S., and Cannon, J. G. (1999). A Neisseria gonorrhoeae immunoglobulin $\mathrm{Al}$ protease mutant is infectious in the human challenge model of urethral infection. Infect. Immun. 67, 3009-3013.

John, C. M., Schneider, H., and Griffiss, J. M. (1999). Neisseria gonorrhoeae that infect men have lipooligosaccharides with terminal $\mathrm{N}$-acetyllactosamine repeats. J. Biol. Chem. 274, 1017-1025.

Johnson, A. P., Taylor-Robinson, D., and McGee, Z. A. (1977). Species specificity of attachment and damage to oviduct mucosa by Neisseria gonorrhoeae. Infect. Immun. 18, 833-839.

Källström, H., Liszewski, M. K., Atkinson, J. P., and Jonsson, A.-B. (1997). Membrane cofactor protein (MCP or CD46) is a cellular pilus receptor for pathogenic Neisseria. Mol. Microbiol. 25, 639-647.

Kim, J. J., Zhou, D., Mandrell, R. E., and Griffiss, J. M. (1992). Effect of exogenous sialylation of the lipooligosaccharide of Neisseria gonorrhoeae on opsonophagocytosis. Infect. Immun. 60, 4439-4442.

Kirchner, M., Heuer, D., and Meyer, T. F. (2005).CD46-independent binding of neisserial type IV pili and the major pilus adhesin, PilC, to human epithelial cells. Infect. Immun. 73, 3072-3082.

Klebanoff, S. J., Hillier, S. L., Eschenbach, D. A., and Waltersdorph, A.M. (1991). Control of the microbial flora of the vagina by $\mathrm{H} 2 \mathrm{O} 2$-generating lactobacilli. J. Infect. Dis. 164, 94-100.

Kline, K.A.,Sechman, E.V.,Skaar,E.P., and Seifert, H. S. (2003). Recombination, repair and replication in the pathogenic Neisseriae: the 3 R's of molecular genetics of two human-specific bacterial pathogens. Mol. Microbiol. 50, 3-13.

Knapp, J. S., and Clark, V. L. (1984). Anaerobic growth of Neisseria gonorrhoeae coupled to nitrite reduction. Infect. Immun. 46, 176-181.

Konishi, H., Matsuzaki, H., Tanaka, M., Takemura, Y., Kuroda, S., Ono, Y. and Kikkawa, U. (1997). Activation of protein kinase B (Akt/RAC-protein kinase) by cellular stress and its asso- ciation with heat shock protein Hsp27. FEBS Lett. 410, 493-498.

Kuhlewein, C., Rechner, C., Meyer, T. F., and Rudel, T. (2006). Low-phosphatedependent invasion resembles a general way for Neisseria gonorrhoeae to enter host cells. Infect. Immun. 74 4266-4273.

LaCalle, R. A., Mira, E., Gómez-Moutón, C., Jiménez-Baranda, S., Martínez-A C., and Mañes, S. (2002). Specific SHP-2 partitioning in raft domains triggers integrin-mediated signaling via Rho activation. J. Cell Biol. 157, 277-289.

Lee, S. W., Higashi, D. L., Snyder, A., Merz, A. J., Potter, L., and So, M. (2005). PilT is required for $\mathrm{PI}(3,4,5) \mathrm{P} 3$-mediated crosstalk between Neisseria gonorrhoeae and epithelial cells. Cell. Microbiol. 7, 1271-1284.

Lin, L., Ayala, P., Larson, J., Mulks, M., Fukuda, M., Carlsson, S. R., Enns, C. and So, M. (1997). The Neisseria type 2 IgA1 protease cleaves LAMP1 and promotes survival of bacteria within epithelial cells. Mol. Microbiol. 24, 1083-1094.

Louv, W. C., Austin, H., Perlman, J., and Alexander, W. J. (1989). Oral contraceptive use and the risk of chlamydial and gonococcal infections. Am. J. Obstet. Gynecol. 160, 396-402.

McCaw, S.E., Liao, E. H., and Gray-Owen, S. D. (2004). Engulfment of Neisseria gonorrhoeae, revealing distinct processes of bacterial entry by individual carcinoembryonic antigen-related cellular adhesion molecule family receptors. Infect. Immun. 72 2742-2752.

McGee, Z. A., Johnson, A. P., and TaylorRobinson, D. (1981). Pathogenic mechanisms of Neisseria gonorrhoeae, observations on damage to human fallopian tubes in organ culture by gonococci of colony type 1 or type 4 . J. Infect. Dis. 143, 413-422.

McQuillen, D. P., Gulati, S., Ram, S. Turner, A. K., Jani, D. B., Heeren, T C., and Rice, P. A. (1999). Complement processing and immunoglobulin binding to Neisseria gonorrhoeae determined in vitro simulates in vivo effects. J. Infect. Dis. 179, 124-135.

Merz, A. J., Rifenbery, D. B., Arvidson, C. G., and So, M. (1996). Traversal of a polarized epithelium by pathogenic Neisseriae, facilitation by type IV pili and maintenance of epithelial barrier function. Mol. Med. 2, 745-754.

Minor,S.Y., Banerjee,A., and Gotschlich,E. C. (2000). Effect of $\alpha$-oligosaccharide phenotype of Neisseria gonorrhoeae strain MS11 on invasion of Chang conjunctival, HEC-1-B endometrial, and ME-180 cervical cells. Infect. Immun. 68, 6526-6534.
Morse, S. A., and Brooks, G. F. (1985). "Neisseria gonorrhoeae taxonomy, colony phenotypes and disease," in Gonococcal Infection, eds G. F. Brooks and E. A. Donegan (London: Butler and Tanner, Ltd.), 3-8.

Morrison, C. S., Bright, P., Wong, E. L., Kwok, C., Yacobson, I., Gaydos, C. A., Tucker, H. T., and Blumenthal, P. D. (2004). Hormonal contraceptive use, cervical ectopy, and the acquisition of cervical infections. Sex. Transm. Dis. 31, 561-567.

Moule, S. K., Welsh, G. I., Edgell, N. J., Foulstone, E. J., Proud, C. G., and Denton, R. M. (1997). Regulation of protein kinase $B$ and glycogen synthase kinase- 3 by insulin and betaadrenergic agonists in rat epididymal fat cells. Activation of protein kinase B by wortmannin-sensitive and -insensitive mechanisms. J. Biol. Chem. 272, 7713-7719.

Muench, D. F., Kuch, D. J., Wu, H., Begum, A. A., Veit, S. J., Pelletier, M. E., SolerGarcía, A. A., and Jerse, A. E. (2009). Hydrogen peroxide-producing lactobacilli inhibit gonococci in vitro but not during experimental genital tract infection. J. Infect. Dis. 199, 1369-1378.

Muenzner, P., Bachmann, V., Kuespert, K., and Hauck, C. R. (2008). The CEACAM1 transmembrane domain, but not the cytoplasmic domain, directs internalization of human pathogens via membrane microdomains. Cell. Microbiol. 10, 1074-1092.

Muenzner, P., Dehio, C., Fujiwara, T. Achtman, M., Meyer, T. F., and GrayOwen, S. D. (2000). Carcinoembryonic antigen family receptor specificity of Neisseria meningitidis Opa variants influences adherence to and invasion of proinflammatory cytokine-activated endothelial cells. Infect. Immun. 68, 3601-3607.

Naids, F. L., Belisle, B., Lee, N., and Rest, R. (1991). Interactions of Neisseria gonorrhoeae with human neutrophils, studies with purified PII (Opa) outer membrane proteins and synthetic Opa peptides. Infect. Immun. 59,4628-4635.

Nikolaitchouk, N., Andersch, B., Falsen, E.,Strömbeck, L., and Mattsby-Baltzer, I. (2008). The lower genital tract microbiota in relation to cytokine-, SLPI- and endotoxin levels: application of checkerboard DNA-DNA hybridization (CDH). APMIS 116, 263-277.

O’Hanlon, D. E., Lanier, B. R., Moench, T. R., and Cone, R.A. (2010) Cervicovaginal fluid and semen block the microbicidal activity of hydrogen peroxide produced by vaginal lactobacilli. BMC Infect. Dis. 10, 120. doi: 10.1186/1471-2334-10-120 
Overton, T. W., Whitehead, R., Li, Y., Snyder, L. A. S., Saunders, N. J., Smith, H., and Cole J.A. (2006). Coordinated regulation of the Neisseria gonorrhoeae-truncated denitrification pathway by the nitric oxide-sensitive repressor, NsrR, and nitrite-insensitive NarQ-NarP. J. Biol. Chem. 281, 33115-33126.

Pantelic, M., Kim, Y.-J., Bolland, S., Chen, I., Shively. J., and Chen, T. (2005). Neisseria gonorrhoeae kills carcinoembryonic antigen-related cellular adhesion molecule 1 (CD66a)expressing human $\mathrm{B}$ cells and inhibits antibody production. Infect. Immun. 73, 4171-4179.

Parsons, N. J., Curry, A., Fox, A. J., Jones, D. M., Cole, J.A., and Smith, H. (1992) The serum resistance of gonococci in the majority of urethral exudates is due to sialylated lipopolysaccharide seen as a surface coat. FEMS Microbiol. Lett. 69, 295-299.

Perez-Garcia, M. J., Cena, V., de Pablo, Y., Llovera, M., Comella, J. X., and Soler, R. M. (2004). Glial cell line-derived neurotrophic factor increases intracellular calcium concentration. Role of calcium/calmodulin in the activation of the phosphatidylinositol 3-kinase pathway. J. Biol. Chem. 279, 6132-6142.

Peyron, P., Bordier, C., N'Diaye, E. -N., and Maridonneau-Parini, I. (2000). Nonopsonic phagocytosis of Mycobacterium kansasii by human neutrophils depends on cholesterol and is mediated by CR3 associated with glycosylphosphatidylinositolanchored proteins. J. Immunol. 165, 5186-5191.

Popp, A., Dehio, C., Grunert, F., Meyer, T. F., and Gray-Owen, S. D. (1999). Molecular analysis of neisserial Opa protein interactions with the CEA family of receptors, identification of determinants contributing to the differential specificities of binding. Cell. Microbiol. 1, 169-181.

Ram, S., Mackinnon, F. G., Gulati, S., McQuillen, D. P., Vogel, U., Frosch, M., Elkins, C., Guttormsen, H.-K., Wetzler, L. M., Oppermann, M., Pangburn, M. K., and Rice, P.A. (1999). The contrasting mechanisms of serum resistance of Neisseria gonorrhoeae and group B Neisseria meningitidis. Mol. Immunol. 36, 915-928.

Ramsey, K. H., Schneider, H., Cross, A. S., Boslego, J. W., Hoover, D. L., Staley, T. L., Kuschner, R. A., and Deal, C. D. (1995). Inflammatory cytokines produced in response to experimental human gonorrhea. J. Infect. Dis. 172, 186-191.

Rechner, C., Kühlewein, C., Müller, A., Schild, H., and Rudel, T. (2007). Host glycoprotein Gp96 and scavenger receptor SREC interact with PorB of disseminating Neisseria gonorrhoeae in an epithelial invasion pathway. Cell Host Microbe 2, 393-403.

Reshef,E., Lei, Z.M., Rao, Ch.V., Pridham, D. D., Chegini, N., and Luborsky, J. L. (1990). The presence of gonadotropin receptors in nonpregnant human uterus, human placenta, fetal membranes, and decidua. J. Clin Endocrinol. Metab. 70, 421-430.

Rest, R. F., Fischer, S. H., Ingham, Z. Z., and Jones, J. F. (1982). Interactions of Neisseria gonorrhoeae with human neutrophils: effects of serum and gonococcal opacity on phagocyte killing and chemiluminescence. Infect. Immun. 136, 737-744.

Rest, R. F., and Frangipane, J. V. (1992). Growth of Neisseria gonorrhoeae in CMP-N-acetylneuraminic acid inhibits nonopsonic (opacity-associated outer membrane protein-mediated) interactions with human neutrophils. Infect. Immun. 60, 989-997.

Sable, C. L., Filippa, N., Hemmings, B., and Van Obberghen, E. (1997). cAMP stimulates protein kinase $B$ in a wortmannin-insensitive manner. FEBS Lett. 409, 253-257.

Sadarangani, M., Pollard, A. J., and GrayOwen, S. D. (2010). Opa proteins and CEACAMs: pathways of immune engagement for pathogenic Neisseria. FEMS Microbiol. Rev. 35, 498-514.

Schmidt, K. A., Deal, C. D., Kwan, M., Thattassery, E., and Schneider, $\mathrm{H}$. (2000). Neisseria gonorrhoeae MS11mkC opacity protein expression in vitro and during human volunteer infectivity studies. Sex. Transm. Dis. 27, 278-283.

Schmitter, T., Pils, S., Weibel, S., Agerer, F., Peterson, L., Buntru, A., Kopp, K., and Hauck, C. R. (2007). Opa proteins of pathogenic Neisseriae initiate Src kinase-dependent or lipid raftmediated uptake via distinct human carcinoembryonic antigen-related cell adhesion molecule isoforms. Infect. Immun. 75, 4116-4126.

Schneider, H., Cross, A. S., Kuschner, R. A., Taylor, D. N., Sandoff, J. C., Boslego, J. W., and Deal, C. D. (1995). Experimental human gonococcal urethritis: 250 Neisseria gonorrhoeae MS11mkC are infective. J. Infect. Dis. 172, 180-185.

Schneider, H., Griffiss, J. M., Boslego, J. W., Hitchoock, P. J., Zahos, K. M., and Apicella, M. A. (1991). Expression of paragloboside-like lipooligosaccharides may be a necessary component of gonococcal pathogenesis in men. $J$. Exp. Med. 174, 1601-1605.

Schneider, H., Hammack, C. A., Apicella, M. A., and Griffiss, J. M. (1988).
Instability of expression of lipooligosaccharides and their epitopes in Neisseria gonorrhoeae. Infect. Immun. 56, 942-946.

Schneider, H., Schmidt, K. A., Skillman, D. R., Van De Verg, L., Warren, R. L., Wylie, H. J., Sadoff, J. C., Deal, C. D., and Cross, A. S. (1996). Sialylation lessens the infectivity of Neisseria gonorrhoeae MS11mkC. J. Infect. Dis. 173, 1422-1427.

Seib, K. L., Simons, M. P., Wu, H. J., McEwan, A. G., Nauseef, W. M., Apicella, M. A., and Jennings, M. P. (2005). Investigation of oxidative stress defenses of Neisseria gonorrhoeae by using a human polymorphonuclear leukocyte survival assay. Infect. Immun. 73, 5269-5272.

Seib, K. L., Wu, H. J., Kidd, S. P., Apicella, M. A., Jennings, M. P., and McEwan, A. G. (2006). Defenses against oxidative stress in Neisseria gonorrhoeae: a system tailored for a challenging environment. Microbiol. Mol. Biol. Rev. 70 , 344-361.

Seib, K. L., Wu, H. J., Srikhanta, Y., Edwards, J. L., Falsetta, M. L. Hamilton, A. J., Maguire, T. L., Grimmond, S. M., Apicella, M. A., McEwan, A. G., and Jennings, M. P. (2007). Characterization of the OxyR regulon of $\mathrm{N}$. gonorrhoeae. Mol. Microbiol. 63, 54-68.

Seifert, H. S., Wright, C. J., Jerse, A. E., Cohen, M. S., and Cannon, J. G. (1994). Multiple gonococcal pilin antigenic variants are produced during experimental human infections. $J$. Clin. Invest. 93, 2744-2749.

Shafer, W. M., and Rest, R. F. (1989). Interactions of gonococci with phagocytic cells. Annu. Rev. Microbiol. 43, 121-145.

Shell, D. M., Chiles, L., Rudd, R. C., Seal, S., and Rest, R. F. (2002). The Neisseria lipooligosaccharide-specific alpha-2,3-sialyltransferase is a surface exposed outer membrane protein. Infect. Immun. 70, 3744-3751.

Simms, A. N., and Jerse, A. E. (2006). In vivo selection for Neisseria gonorrhoeae opacity protein expression in the absence of human carcinoembryonic antigen cell adhesion molecules. Infect. Immun. 74, 2965-2974.

Skaletz-Rorowski, A., Lutchman, M., Kureishi, Y., Lefer, D. J., Faust, J. R., and Walsh, K. (2003). HMG-CoA reductase inhibitors promote cholesterol-dependent Akt/PKB translocation to membrane domains in endothelial cells. Cardiovasc. Res. 57, 253-264.

Skarin, A., and Sylwan, J. (1986). Vaginal lactobacilli inhibiting growth of Gardnerella vaginalis, Mobiluncus and other bacterial species cultured from vaginal content of women with bacterial vaginosis. Acta Pathol. Microbiol. Immunol. Scand. B 94 399-403.

Spence, J. M., Chen, J. C.-R., and Clark, V. L. (1997). A proposed role for the lutropin receptor in contact-inducible gonococcal invasion of $\mathrm{HeclB}$ cells. Infect. Immun. 65, 3736-3742.

Spence, J. M., Tyler, R. E., Domaoal, R. A., and Clark, V. L. (2002). L12 enhances gonococcal transcytosis of polarized Hec1B cells via the lutropin receptor. Microb. Pathog. 32, 117-125.

Srikhanta, Y. N., Fox, K. L., and Jennings, M. P. (2010). The phasevarion: phase variation of type III DNA methyltransferases controls coordinated switching in multiple genes. Nat. Rev. Microbiol. 8, 196-206.

Steichen, C. T., Shao, J. Q., Ketterer, M. R., and Apicella, M. A. (2008). Gonococcal cervicitis: a role for biofilm in pathogenesis. J. Infect. Dis. 198, 1856-1861.

Stephens, D. S., McGee, Z. A., and Cooper, M. D. (1987). Cytopathic effects of pathogenic Neisseria. Studies using human fallopian tube organ cultures and nasopharyngeal organ cultures. Antonie Van Leeuwenhoek 53,575-584.

Swanson, J. (1977). Surface components affecting interactions between Neisseria gonorrhoeae and eucaryotic cells. J. Infect. Dis. 136(Suppl.), S138-S143.

Swanson, K. V., Jarvis, G. A., Brooks, G. F., Barham, B. J., Cooper, M. D., and Griffiss, J. M. (2001). CEACAM is not necessary for Neisseria gonorrhoeae to adhere to and invade female genital epithelial cells. Cell. Microbiol. 3, 681-691.

Timmerman, M. M., Shao, J. Q., and Apicella, M. A. (2005). Ultrastructural analysis of the pathogenesis of Neisseria gonorrhoeae endometrial infection. Cell. Microbiol. 7, 627-636.

Väisänen-Tommiska, M., Nuutila, M., Aittomäki, K., Hiilesmaa, V., and Ylikorkala, O. (2003). Nitric oxide metabolites in cervical fluid during pregnancy: further evidence for the role of cervical nitric oxide in cervical ripening. Am. J. Obstet. Gynecol. 188, 779-785.

van Putten, J. P. (1993). Phase variation of lipopolysaccharide directs interconversion of invasive and immunoresistant phenotypes of Neisseria gonorrhoeae. EMBO J. 12, 4043-4051. van Putten, J. P. M., Duensing, T. D., and Carlson, J. (1998a). Gonococcal invasion of epithelial cells driven by P.IA, a bacterial ion channel with GTP binding properties. J. Exp. Med. 188, 941-952. 
van Putten, J. P. M., Duensing, T. D., and Cole, R. L. (1998b). Entry of Opa ${ }^{+}$ gonococci into Hep-2 cells requires concerted action of glycosaminoglycans, fibronectin and integrin receptors. Mol. Microbiol. 29, 369-379.

van Putten, J. P. M., and Robertson, B. D. (1995). Molecular mechanisms and implications for infection of lipopolysaccharide variation in Neisseria. Mol. Microbiol. 16, 847-853.

Virji, M. (2009). Pathogenic neisseriae: surface modulation, pathogenesis and infection control. Nat. Rev. Microbiol. 7, 274-286.

Virji, M., Evans, D., Hadfield, A., Grunert, F., Teixeira, A. M., and Watt, S. M. (1999). Critical determinants of host receptor targeting by Neisseria meningitidis and Neisseria gonorrhoeae: identification of Opa adhesiotopes on the $\mathrm{N}$-domain of CD66 molecules. Mol. Microbiol. 34, 538-551.

Virji, M., and Heckels, J. E. (1986). The effect of protein II and pili on the interaction of Neisseria gonorrhoeae with human polymorphonuclear leucocytes. J. Gen. Microbiol. 132, 503-512.
Virji, M., Watt, S. M., Barker, S., Makepeace, K., and Doyonnas, R. (1996). The N-domain of the human CD66a adhesion molecule is a target for Opa proteins of Neisseria meningitidis and Neisseria gonorrhoeae. Mol. Microbiol. 22, 929-939.

Vogel, U., and Frosch, M. (1999). Mechanisms of neisserial serum resistance. Mol. Microbiol. 32, 1133-1139.

Wang, J., Gray-Owen, S. D., Knorre, A., Meyer, T. F., and Dehio, C. (1998). Opa binding to cellular CD66 receptors mediates the transcellular traversal of Neisseria gonorrhoeae across polarized T84 epithelial cell monolayers. Mol. Microbiol. 30, 657-671.

Wang, J. A., Meyer, T. F., and Rudel, T. (2007). Cytoskeletal and motor proteins are required for the transcytosis of Neisseria gonorrhoeae through polarized epithelial cells. Int. J. Med. Microbiol. 298, 209-221.

Ward, M.E., Robertson, J. N., Englefield, P. M., and Watt, P.J. (1975). "Gonococcal infection: invasion of the mucosal surfaces of the genital tract," in Microbiology ed. D. Schlessinger
(Washington DC: ASM Press), 188-199.

Woods, M. L. II, and McGee, Z. A. (1986). Molecular mechanisms of pathogenicity of gonococcal salpingitis. Drug 31(Suppl. 2), 1-6.

Wu, H., and Jerse, A. E. (2006). Alpha-2,3sialyltransferase enhances Neisseria gonorrhoeae survival during experimental murine genital tract infection. Infect. Immun. 74, 4094-4103.

Wu, H.-J, Seib, K. L., Edwards, J. L., Apicella, M. A., McEwan, A. G., and Jennings, M. P. (2005). Azurin of pathogenic Neisseria is involved in defense against hydrogen peroxide and survival within cervical epithelial cells. Infect. Immun. 73, 8444-8448.

Wu, H.-J, Seib, K. L., Srikhanta, Y. N. Kidd, S. P., Edwards, J. L., Maguire, T. L., Grimmond, S. M., Apicella, M. A., McEwan, A. G., and Jennings, M P. (2006). The PerR regulon controls Mn-dependent resistance to oxidative stress in Neisseria gonorrhoeae. Mol. Microbiol. 60, 401-416.

Zass, D. W., Duncan, M., Wright, J. R., and Abraham, S. N. (2005). The role of lipid rafts in the pathogenesis of bacterial infections. Biochim. Biophys. Acta 1746, 305-313.

Conflict of Interest Statement: The authors declare that the research was conducted in the absence of any commercial or financial relationships that could be construed as a potential conflict of interest.

Received: 15 February 2011; paper pending published: 28 February 2011; accepted: 25 April 2011; published online: 10 May 2011.

Citation: Edwards JL and Butler EK (2011) The pathobiology of Neisseria gonorrhoeae lower female genital tract infection. Front. Microbio. 2:102. doi: 10.3389/ fmicb.2011.00102

This article was submitted to Frontiers in Cellular and Infection Microbiology, a specialty of Frontiers in Microbiology.

Copyright $(2011$ Edwards and Butler. This is an open-access article subject to a non-exclusive license between the authors and Frontiers MediaSA, which permits use, distribution and reproduction in other forums, provided the original authors and source are credited and other Frontiers conditions are complied with. 